\title{
Vertical subluxation of the axis in rheumatoid arthritis
}

\author{
D. R. SWINSON,* E. B. D. HAMILTON,* J. A. MATHEWS $\dagger$, And D. A. H. YATES $\dagger$ \\ From the *Department of Physical Medicine and Rheumatology, King's College Hospital, and the $\dagger$ Department \\ of Rheumatology and Physical Medicine, St. Thomas' Hospital, London
}

Involvement of the upper cervical spine in rheumatoid arthritis is now well documented and recognized as a common feature of the disease. Forward subluxation of the atlas on the axis on flexion of the neck is one of the most frequent and characteristic findings, occurring in 25 per cent. of a series of patients reported by Conlon, Isdale, and Rose (1966) and confirmed by Mathews (1969) in a tomographic study. Backward displacement of the atlas on the axis has been described in two cases of severe rheumatoid arthritis by Isdale and Corrigan (1970) and in one patient by Crellin, Maccabe, and Hamilton (1970).

Minor degrees of vertical subluxation of the axis have been found in radiological studies by several authors including, Sharp and Purser (1961), Bland, Davis, London, Van Buskirk, Duarte, and Burlington (1963), and Martel (1961). Mathews (1969) found that the odontoid peg protruded above the level of the foramen magnum in 5 per cent. of his 76 cases. The particular danger of this lesion was emphasized by Ball and Sharp (1971) and compression of the brainstem and cord by a vertically subluxed odontoid peg was considered to be the main cause of death in the cases reported by David and Markley (1951), Storey (1958), and Martel and Abell (1963), although in the case reported by Webb, Hickman, and Brew (1968) death was due to massive thrombosis of the distorted vertebral arteries. Rana and Taylor (1971) described a case of vertical migration of the odontoid process associated with acute cord compression, which was relieved by skull traction and posterior occipito-atlanto-axial fusion. Another non-fatal case reported by Newman and Sweetman (1969) showed subjective improvement after occipito-cervical fusion.

In general, the outlook for these patients, as judged by these case reports, is poor. Two patients are therefore reported below who, despite alarming radiological signs, have survived with conservative care. A third patient who has improved after occipital decompression is also described.

\section{Case reports}

Case 1, a 60-year old woman, had a 15-year history of severe classical rheumatoid arthritis. Despite treatment

Accepted for publication January 21, 1972. with gold and corticosteroids she had become progressively disabled and was virtually chairbound.

Five years ago she first developed neck pain which was aching in character and radiated behind both ears. In 1968 she had episodes of faintness when looking to the left, together with transient complete right hemianaesthesiae. These included involvement of tongue and throat, as well as paraesthesiae in her right hand. In 1969 she experienced two attacks of hemianaesthesiae accompanied by falling to the ground, although consciousness was not lost. Since then she has not experienced hemianaesthesiae but now suffers from faintness when looking down and occasional bilateral facial paraesthesiae. For 12 months she had had intermittent blurring of vision.

\section{Examination}

She was hypercorticoid and had a severe widespread arthritis mutilans. Her neck was held rigid and there was a greatly reduced range of movement in all directions, particularly to the left. No abnormal neurological signs could be detected. $X$ rays of the cervical spine in 1971 showed no atlanto-axial subluxation, but the odontoid peg was projecting $5 \mathrm{~mm}$. through the foramen magnum (Fig. 1). Tomography showed pitting of the odontoid due to erosions and flattening of the anterior surface. It was suggested that this might have been due to pressure from the anterior lip of the foramen magnum.

\section{Treatment}

In view of the absence of progressive symptoms and signs, it was decided to treat the patient conservatively in a collar. There has been no subsequent deterioration.

Case 2, a 64-year old woman, had a 21-year history of severe classical rheumatoid arthritis. She was housebound and severely disabled. Treatment had included gold and systemic corticosteroids.

She first complained of aching in the neck in 1961 but it was not until 1968 that the pain became severe with radiation to the shoulders. The pain was made worse by neck movement and sitting forward, but was not affected by jolting. Over the next 2 years the pain subsided but she then developed faintness on looking down; this symptom also disappeared.

\section{Examination}

She was a small, wasted woman with severe arthritis mutilans. Her head and shoulders had a hunched appearance and movement of the head was surprisingly free and painless. Lateral rotation was restricted to $30^{\circ}$ on either 


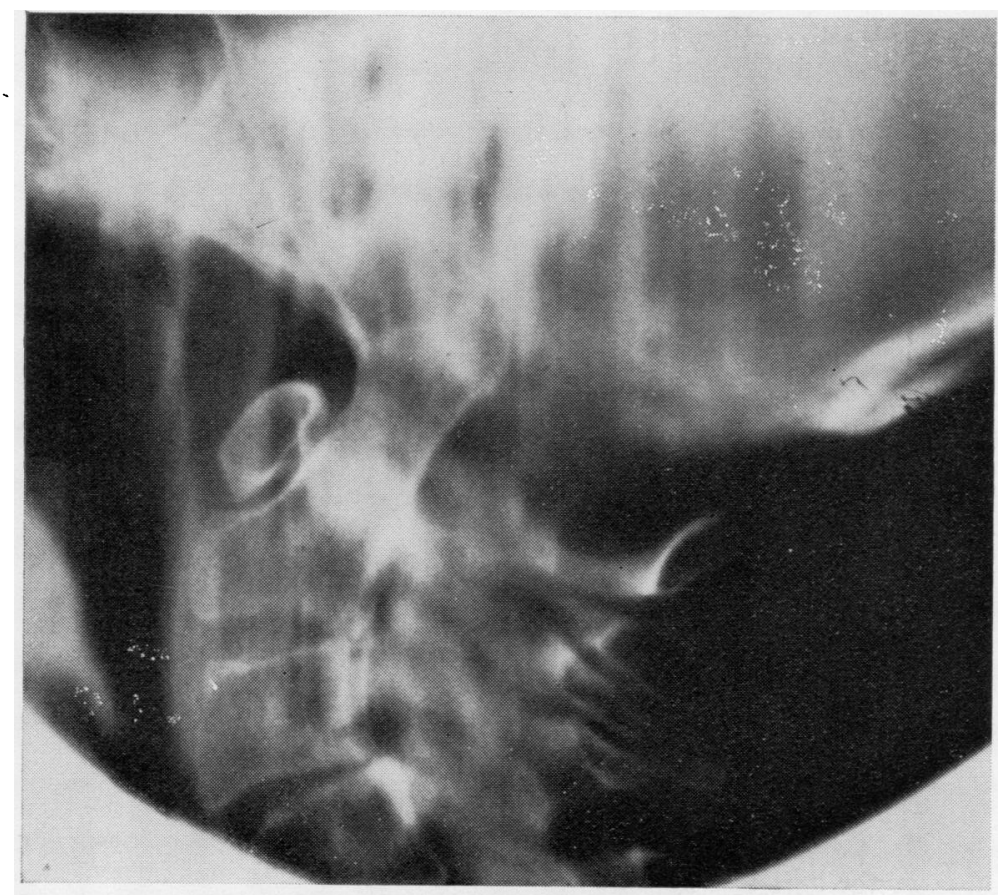

FIG. 1 Odontoid process projecting $5 \mathrm{~mm}$. through the foramen magnum

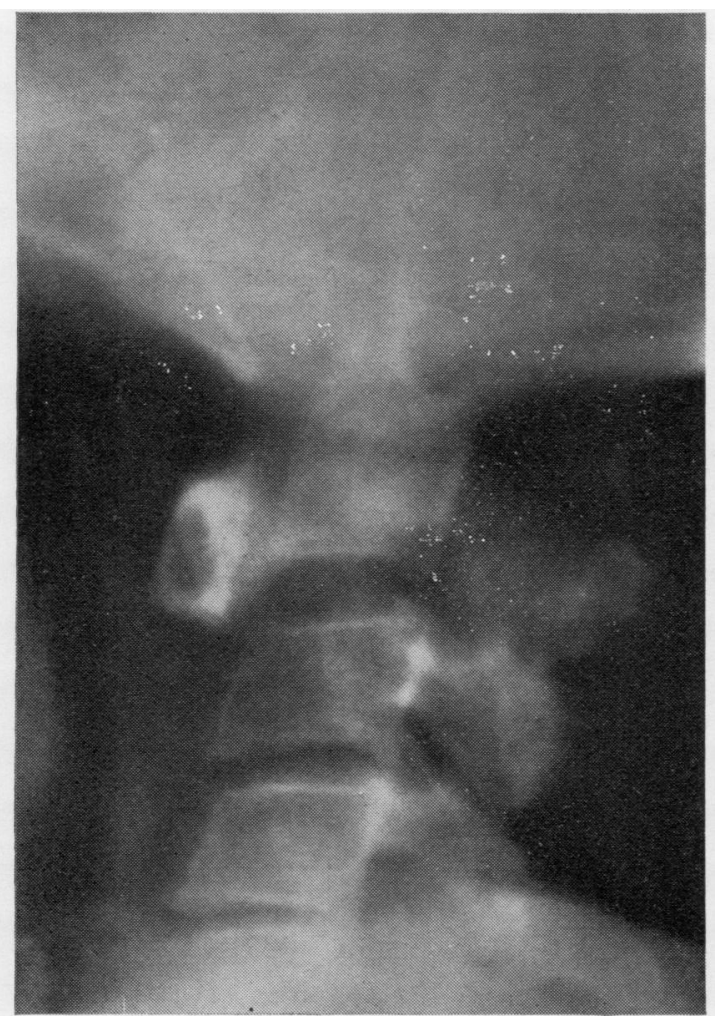

FIG. 2 The body of the axis has passed through the arch of the atlas side but lateral flexion, flexion, and extension were only slightly reduced. The most painful joints were the knees, which were unstable and showed flexion deformities. No abnormal neurological signs could be detected. $X$ rays

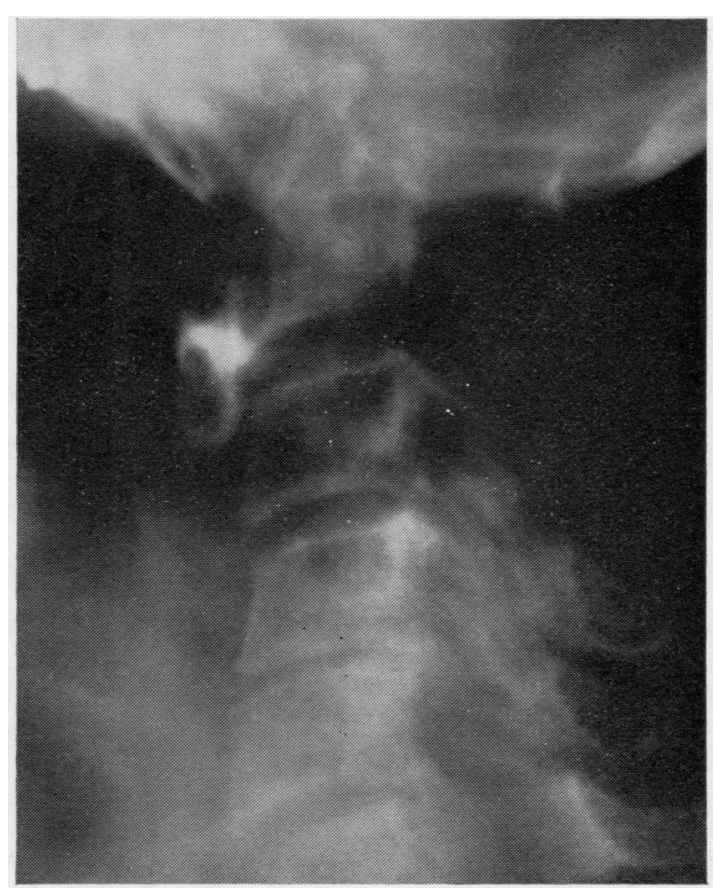

FIG. 3 Body of C3 passing through the arch of the atlas 
showed no antero-posterior subluxation in the upper cervical spine, but there was marked upward migration of the odontoid peg with passage of the body of C2 through the arch of the atlas (Fig. 2). Eighteen months later, in February, 1971, the condition had progressed with the body of $\mathrm{C} 3$ following $\mathrm{C} 2$ through the atlas (Fig. 3).

\section{Treatment}

In the absence of neurological complications this patient was also treated conservatively with a collar.

\section{Result}

There has been no clinical deterioration.

Case 3, a man aged 48 years, had a 14-year history of seronegative, anodular, rheumatoid arthritis. There was a severely destructive peripheral arthritis, and also a remarkable degree of spinal stiffness suggestive of spondylitis-but with negative sacroiliac tests and $x$ rays. Joint destruction had led to bilateral hip replacements and a knee arthroplasty. He had been taking 10 to $15 \mathrm{mg}$ prednisolone (or equivalent) daily since early in the disease, and had needed insulin for a consequent diabetes mellitus.

In 1970 he began to complain of jumping of the hips at night and numbness of the right forearm and right and left finger tips; he also reported paraesthesiae of the legs on coughing, and these paraesthesiae could be produced by spinal movement. By May, 1970, the plantar responses had become extensor, and in August, 1970, he was admitted and found to have evidence of a bulbar lesion with loss of pharyngeal sensation and symmetrical uvular elevation. There was also evidence of a progressive cord lesion with clinical and electrodiagnostic signs of a

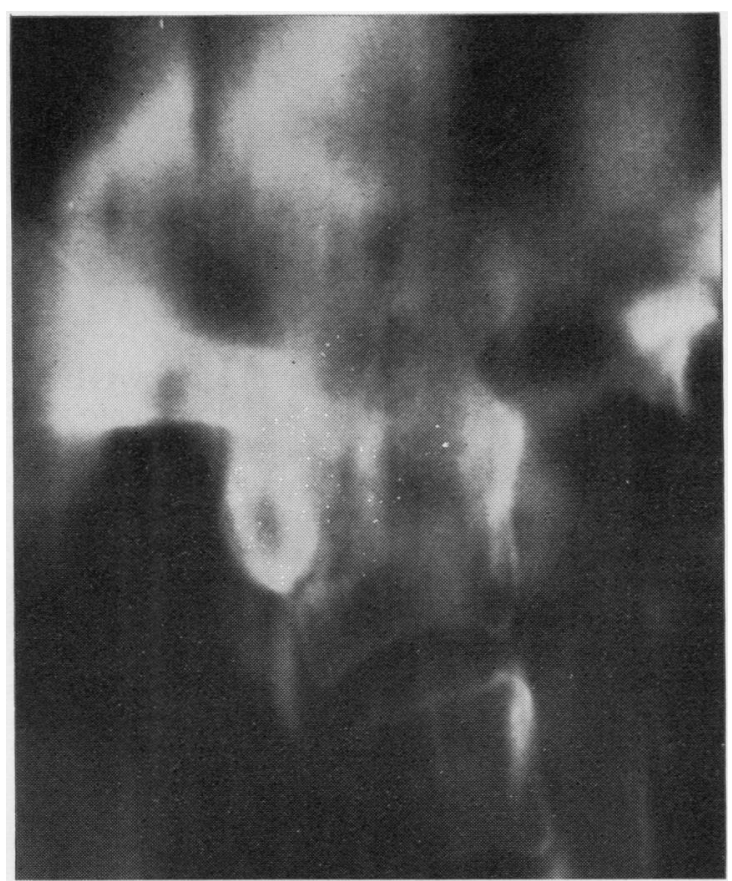

FIG. 4 There is gross vertical subluxation of the odontoid process multiradicular lesion in both arms with denervation in the C6/7/8 territory. There was hyper-reflexia in the legs and the plantar responses were extensor. Cervical $x$ rays showed vertical subluxation of the odontoid process (Fig. 4) and gross anterior sub-luxation of C4 upon C5 (Fig. 5, overleaf) with a myelographic block (Fig. 6, overleaf).

\section{Treatment}

He was transferred to the care of Mr. Lindsay Symon, who (after initial skull traction) decompressed the foramen magnum as the bulbar lesion was considered the greater threat to life. Postoperatively the patient wore a rigid cervical collar.

\section{Result}

Progress has been favourable, with sufficient return of function to make him almost independent for daily activities. Power is returning to the arms, the plantar responses are flexor and the bulbar signs have disappeared.

\section{Discussion}

On theoretical grounds two groups of patients with atlanto-axial subluxation can be distinguished. The first and commoner group has varying degrees of forward subluxation of the atlas. The cartilage covered opposing surfaces of the atlanto-axial apophyseal joints are convex and horizontal (Coutts, 1934) and prevention of subluxation therefore relies entirely on ligamentous integrity. Destruction or softening of the transverse ligament, alar ligaments, and apophyseal capsules by local synovitis suffices for subluxation to take place. This mechanism is illustrated by the spontaneous atlanto-axial subluxation occurring without bone destruction in children with nasopharyngeal inflammation (Berkheiser and Seidler, 1931; Watson Jones, 1932) and by the increased gap between the odontoid and the anterior arch of the atlas found in adolescents and young adults when compared with the older age groups (Sharp and Purser, 1961; Jackson, 1950).

The second group, consisting of patients with vertical or backward subluxation of atlas on the axis, is much smaller in number and bone and cartilage destruction is essential for subluxation to take place. In vertical subluxation the movement cranially is dependent on destruction of the lateral articular masses or of bone around the foramen magnum. In backward luxation there is fracture of the dens or erosion of the arch of the atlas.

Vertebral destruction caused by diseases other than rheumatoid arthritis may also lead to vertical passage of the odontoid. Nonne (1925) described a fatal cause of tuberculous destruction of the atlas associated with upward odontoid migration and death; and basilar invagination caused by Paget's disease of bone or osteogenesis imperfecta (Ray, 1942) may also cause medullary compression. 


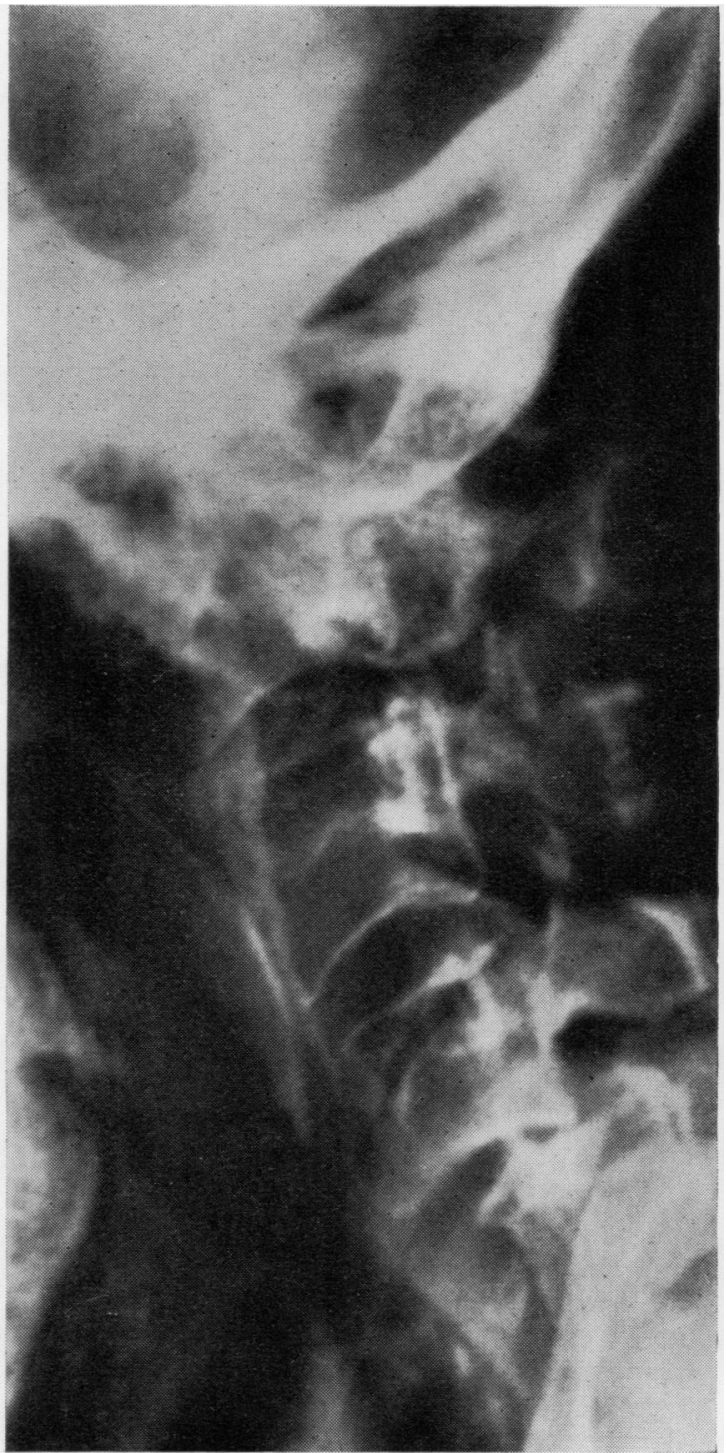

FIG. 5 C4 has subluxed anteriorly

Previous reports of vertical subluxation of the axis have been heavily weighted with reports of death. Our cases serve to show that survival is possible with severe radiological lesions and in two cases with only conservative care. The third patient has done well with decompression of the foramen magnum. His bulbar signs have disappeared and his plantar responses are now flexor. Some of his neurological deficit was probably secondary to the lower cervical subluxation and may have improved from splinting in a collar.

The lack of symptoms in Case 2 and the lack of neurological signs in Cases 1 and 2 are striking considering the degree of subluxation on $x$ ray. This

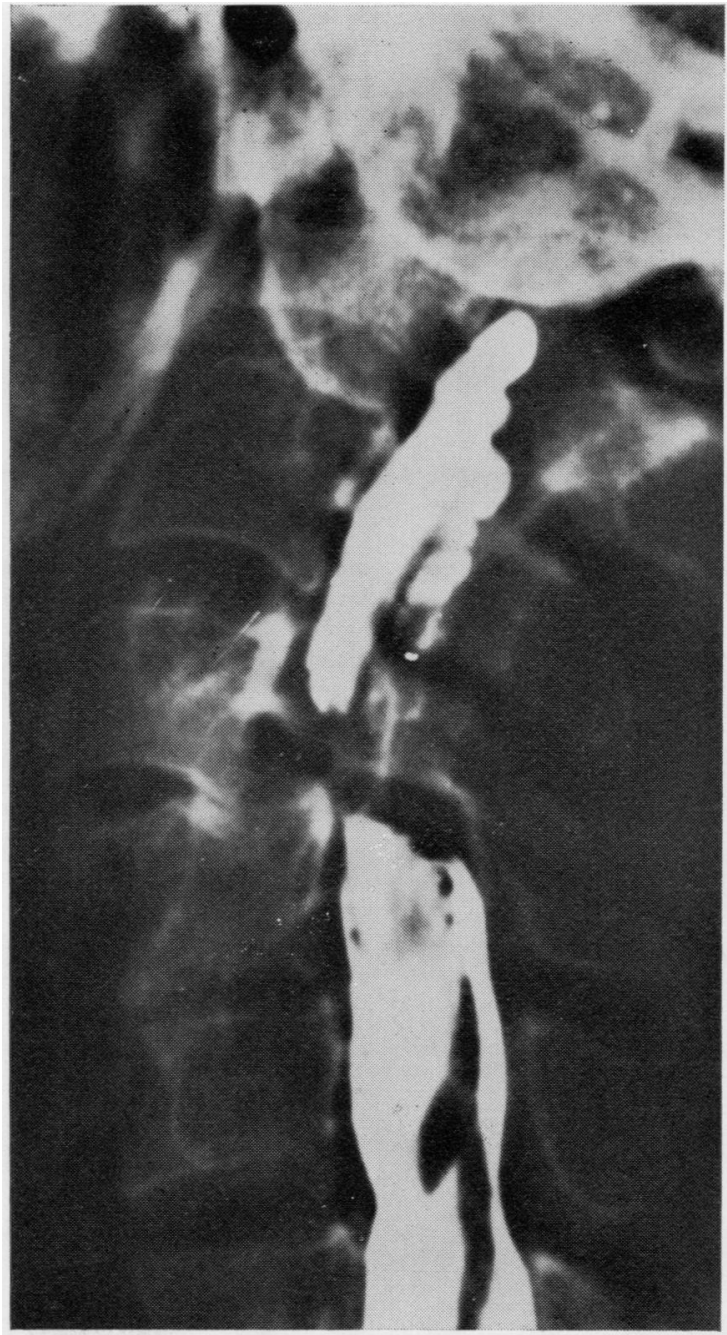

FIG. 6 There is a myelographic block at the C4-5 level

finding is in agreement with that of Mathews (1969), who found little correlation between atlanto-axial disease and neurological deficit, although Sharp and Purser (1961) showed some relationship between the latter and the width of the spinal canal. However, findings to the contrary have been presented by Stevens, Cartlidge, Saunders, Appleby, Hall, and Shaw (1971), who found that 60 per cent of 34 patients with atlanto-axial subluxation had increased tendon reflexes, although these are notoriously difficult to judge in arthritics and are influenced by factors other than myelopathy.

\section{Summary}

Three patients with vertical subluxation of the odontoid process are presented. Despite having 
advanced radiological changes two of these were managed conservatively and the third improved after foramen magnum decompression and immobilization in a rigid collar.

All three have advanced destructive peripheral arthritis and it is emphasized that vertical odontoid subluxation is dependent on vertebral destruction, in contrast to forward subluxation of the atlas on the axis, which can occur without such bony changes.

Serious neurological sequelae do not necessarily occur even with extreme degrees of vertical subluxation.

\section{References}

BaLl, J., AND SharP, J. (1971) 'Rheumatoid arthritis of the cervical spine', in 'Modern Trends in Rheumatology-2' ed A. G. S. Hill, p. 117. Butterworths, London.

Perkheiser, E. J., AND Seidler, F. (1931) J. Amer. med. Ass., 96, 517 (Non-traumatic dislocation of the atlanto-axial joint)

Bland, J. H., Davis, P. H., London, M. G., Van Buskirk, F. W., Duarte, C. G., and Burlington, V. T. (1963) Arch. Intern Med. 112, 892 (Rheumatoid arthritis of the cervical spine)

Conlon, P. W., Isdale, I. C., AND Rose, B. S. (1966) Ann. rheum. Dis., 25, 120 (Rheumatoid arthritis of the cervical spine)

CoutTs, M. B. (1934) Arch. Surg., 29, 297 (Atlanto-epistropheal subluxations)

Crellin, R. Q., Maccabe, J. J., AND Hamilton, E. B. D. (1970) J. Bone J. Surg., 52B, 244 (Severe subluxation of the cervical spine in rheumatoid arthritis)

Davis, F. W., JR., AND MARKLEY, H. E. (1951) Ann. Intern Med., 35, 451 (Rheumatoid arthritis with death from medullary compression)

Isdale, I. C., and Corrigan, B. (1970) Ann. rheum. Dis., 29, 6 (Backward luxation of the atlas)

JACKSON, H. (1950) Brit. J. Radiol., 23, 672 (The diagnosis of minimal atlanto-axial subluxation)

Martel, W. (1961) Amer. J. Roentgenol., 86, 223 (The occipito-atlanto-axial joints in rheumatoid arthritis and ankylosing spondylitis)

- - AND ABELL, M. R. (1963) Arthr. and Rheum., 6, 224 (Fatal atlanto-axial luxation in rheumatoid arthritis)

Mathews, J. A. (1969) Ann. rheum. Dis., 28, 260 (Atlanto-axial subluxation in rheumatoid arthritis)

Newman, P., And Sweetnam, R. (1969) J. Bone Jt Surg., 51B, 423 (Occipito-cervical fusion. An operative technique and its indications)

NonNe, M. (1925) Arch. Psychiat. Nervenkrank., 74, 264 (Kompression des Halsmarks durch eine chronisch entstandere Luxation zwischen Atlas and Epistropheus sowie zwischer Schädelbasis und Atlas)

Rana, N. A., AND TaYlor, A. R. (1971) Proc. roy. Soc. Med., 64, 717 (Upward migration of the odontoid peg in rheumatoid arthritis)

RAY, B. S. (1942) Ann. Surg., 116, 231 (Platybasia with involvement of the central nervous system)

Sharp, J., and PurSer, D. W. (1961) Ann. rheum. Dis., 20, 47 (Spontaneous atlanto-axial dislocation in ankylosing spondylitis in rheumatoid arthritis)

Stevens, J. C., Cartlidge, N. E. F., Saunders, M., Appleby, A., Hall, M., and Shaw, D. A. (1971) Quart. J. Med., n.s. 40, 391 (Atlanto-axial subluxation and cervical myelopathy in rheumatoid arthritis)

Storey, G. (1958) Ann. phys. Med. 4, 216 (Changes in the cervical spine in rheumatoid arthritis with compression of the cord)

Watson Jones, R. (1932) Proc. roy. Soc. Med., 25, 586 (Spontaneous hyperaemic dislocation of the atlas)

WebB, F. W. S., Hickman, J. A., AND BREW, D. St. J. (1968) Brit. med.J., 2, 537 (Death from vertebral artery thrombosis in rheumatoid arthritis) 